\title{
DELEUZE E GUATTARI: ESQUIZOANÁLISE E MAIO DE 68
}

\section{DELEUZE E GUATTARI: \\ SCHIZOANALYSIS AND MAY 68}

\author{
Jhony A. Skeika"
}

Resumo: Este estudo tem o objetivo de promover uma breve discussão a respeito do posicionamento teórico, filosófico e político dos filósofos franceses Gilles Deleuze (1925-1995) e Félix Guattari (1930-1992), principalmente frente ao contexto dos movimentos sociais, estudantis e grevistas acontecidos em Maio de 1968, na França. Busca-se refletir sobre como esse importante período de lutas populares foi marcante para o desenvolvimento e amadurecimento das pesquisas e discussões desses dois intelectuais, tornando-os referências nas áreas das ciências humanas, como Filosofia, Estudos da Linguagem (Línguas e Literaturas), Sociologia, etc., especialmente a partir dos seus estudos sobre Capitalismo e Esquizofrenia: O Anti-Édipo (1972) e Mil Platôs (1980). Palavras-chave: Gilles Deleuze; Félix Guattari; Filosofia; Esquizoanálise; Maio de 1968.

Aвstract: This study aims to promote a brief discussion about the theoretical, philosophical and political commitments of the French authors Gilles Deleuze (19251995) and Félix Guattari (1930-1992), contextualized mainly during the social, student and strike movements that took place in May 1968, in France. The text intends to reflect about how important these notorious popular events were to Deleuze and Guattari's studies, which have made them references in different areas of Human Sciences, such as Philosophy, Languages' Studies (Languages and Literatures), Sociology, etc., specially through their studies about Capitalism and Schizophrenia: Anti-Oedipus (1972) and A Thousand Plateaus (1980).

KEYwords: Gilles Deleuze; Félix Guattari; Philosophy; Schizoanalysis; May 1968.

\footnotetext{
"Pós-doutorando (PNPD). Programa de Pós-Graduação em Estudos da Linguagem (UEPG). Supervisão de pesquisa: Profa.Dra. Silvana Oliveira.E-mail: jhonyskeika@uepg.br / jhonyskeika@hotmail.com
} 


\section{INTRODUÇÃo}

Gilles Deleuze é um importante intelectual francês que publicou uma série de estudos sobre filósofos como Spinoza, Leibniz, Hume, Kant, Nietzsche, Bergson, Foucault e sobre artistas como Proust, Artaud, Kafka e Francis Bacon. Sua parceria com Félix Guattari data do final da década de 1960 e, juntos, aproveitando a vasta experiência política e psiquiátrica de Guattari (psicanalista) iniciaram uma significativa discussão sobre Capitalismo e Esquizofrenia, motivada pelas manifestações ocorridas em Maio de 1968 na França.

Nesse período, movimentos estudantis iniciaram diversas greves em universidades e escolas francesas, após confrontos com a administração pública e com a polícia. Isso gerou uma greve generalizada na França, adquirindo proporções revolucionárias, uma insurreição popular que englobou mais da metade dos trabalhadores franceses. Há muitos teóricos que defendem o envolvimento do Partido Comunista Francês como responsável pela rebelião, embora, aparentemente, o movimento tenha começado dentro das academias francesas, em especial na Universidade de Nanterre, na região metropolitana de Paris.

Das barricadas da comuna estudantil acendeu-se um estopim de protestos generalizados que levou em menos de três semanas a uma greve geral por todo o país o espantoso número de mais de dez milhões de trabalhadores paralisando praticamente todos os setores produtivos da sociedade. Nunca uma potência capitalista estivera sob ameaça tão grave de destruição de suas instituições políticas. Estudantes e trabalhadores em voz uníssona recusaram-se durante mais de um mês a qualquer diálogo com as representações políticas tradicionais nas negociações entre capital e trabalho no capitalismo. (PINTO, 2008, p. 1).

Na ocasião desses acontecimentos, de acordo com François Dosse (2010, p. 155), Deleuze trabalhava na Universidade de Lyon e, prontamente, demonstrou muita empatia para com o movimento estudantil. Além de ser o único professor do Departamento de Filosofia, ele é um dos poucos professores universitários de Lyon a declarar, publicamente, seu apoio aos estudantes, participando das assembleias e passeatas junto aos manifestantes.

Embora sua prioridade seja finalizar sua tese de doutoramento, a ser defendida no outono de 1968, devido ao cansaço causado pelas manifestações, somado à carreira de professor e estudante de doutorado, ainda segundo Dosse (2010, p. 156), Deleuze precisa se ausentar das suas atividades, também porque descobre o retorno de uma antiga tuberculose mal curada, adiando a defesa da sua pesquisa. Em janeiro de 1969, sob um clima de tensão gerado tanto por seu frágil estado de saúde como também pelo medo da banca examinadora de haver uma possível "invasão" da universidade por agitadores, cujo posicionamento era simpático aos estudos desse intelectual, Deleuze apresenta, na Sorbonne, uma das primeiras teses após Maio de 68, problematizando questões muito sensíveis às reinvindicações sociais, mesmo 
estando os confrontos ainda longe de encontrar um fim. Publicada ainda em 1969, Diferença e repetição, a tese de doutoramento de Deleuze, é a sua grande obra de lançamento, por meio da qual ele abre mão de uma abordagem histórica da Filosofia para expressar suas próprias posições teórico-críticas, muitas delas calcadas na experiência dos movimentos sociais que ocuparam as ruas de Paris em Maio de 68.

Há um panorama político, no sentido mais geral do termo, que perpassa os estudos desse filósofo francês, traço esse que vai se intensificar após a defesa da sua tese, quando ele conhece Félix Guattari. Mesmo estando em um momento de enfraquecimento corporal e de afastamento temporário e forçado das atividades acadêmicas, devido a uma séria cirurgia que o deixou com apenas um pulmão e uma insuficiência respiratória permanente, a parceria com Guattari lhe garantiu, metaforicamente, um novo pulmão, um novo fôlego para as lutas filosóficas engajadas que viriam a seguir. François Dosse (2010, p. 157) chega a afirmar que, sem os acontecimentos sociais ocorridos a partir de Maio de 68, talvez o encontro nunca tivesse acontecido, pelo menos não com os mesmos frutos.

\section{ESQUIZOANÁLISE}

A primeira obra escrita em conjunto foi O Anti-Édipo, uma densa discussão sobre as emaranhadas relações entre Capitalismo e Esquizofrenia (DELEUZE; GUATTARI, 2010); é um texto gestado nas efervescências intelectuais e revolucionárias, fruto dos acontecimentos de Maio de 68 que, para os filósofos, se apresentaram como ruptura necessária, um devir libertador. "Maio de 68 nos abalou, a Gilles e a mim, como também a tantos outros. Nós não nos conhecíamos, mas esse livro foi, em todo caso, uma continuação de Maio de 1968". (GUATTARI, 1990, p. 26 apud DOSSE, 2010, p. 157).

Criticando a máquina capitalista, o sistema terapêutico redutor do Complexo de Édipo e também as limitações da teoria marxista, esse livro representa uma ruptura com as discussões epistemológicas traçadas pela Filosofia ocidental do século XX, além de criticar veementemente os prestígios da psicanálise. Etnologia, política, linguística, economia, literatura, artes, etc. são alguns dos muitos campos do saber que perpassam o livro, em favor da derrocada do Édipo, como diz Maurice de Gandillac, ex-orientador de tese de Deleuze. Para Analice de Lima Palombini (2009, p. 39), O Anti-Édipo era a peste para a psicanálise,

Mas a potência crítica desse livro escrito a quatro mãos viu-se enfraquecida, na medida em que o Édipo mesmo foi perdendo força como lei reguladora do social - perda que é ainda motivo de lamentação de psicanalistas nostálgicos do pai. O furacão virou brisa leve para uma psicanálise que, mal ou bem, segue de pé. 
Mesmo não sendo médico como seu colega de pesquisa, a parceria estabelecida com Guattari leva Deleuze a se ocupar da crítica à psicanálise, em especial, para além dos seus conceitos, a seus desdobramentos clínico-políticos. Na sequência de O Anti-Édipo, Mil Platôs, publicado em 1980, já está mais dedicado à criação ou aprofundamento de noções - não conceitos - como as ideias de corpo-sem-órgãos, rizoma, devir, (des/re)territorialização, agenciamento, multiplicidade, etc. De um platô a outro, pode-se rastrear o debate com a psicanálise, o qual aparece, com maior ou menor ênfase, seja como plano de fundo, seja como área de (des/ re)territorialização e mapeamentos.

Assim como os movimentos sociais que foram às ruas de Paris abalaram as estruturas opressoras, fazendo circular pelos poros das máquinas do Estado um fluxo contrário, uma força de cisão (esquizofrênica ${ }^{1}$ ), a filosofia de Deleuze e Guattari propõe algo novo, não no fim ou no começo, mas "se encontra sempre no meio, entre as coisas, inter-ser, intermezzo" (DELEUZE; GUATTARI, 1995, p. 37). Eles questionam os conceitos de sujeito, indivíduo e de centralidade (sistema árvore), intencionando circular nos entremeios, nos desejos, nas linhas de fuga, nos devires (des/re)territorializados.

Para os autores, a psique dos sujeitos é uma fábrica em constante produção (movida pelo desejo), e não um palco de representações, como propunha Freud - daí suas críticas a uma psicanálise que reivindica o controle, a todo tempo, desse "ser" interior e que centraliza toda manifestação psicológica no ponto comum do Complexo de Édipo. Deleuze e Guattari são os filósofos que bem representam Maio de 1968, pois seus conceitos funcionam como rizomas: uma raiz que se espalha sem hierarquia ou algum centro de comando e, por isso, sem direção definida - o contrário daquilo que defendia Descartes: a filosofia como uma árvore.

Para Deleuze e Guattari, Filosofia é rizoma, pois não há formas fixas, só linhas de segmentação, conexão e linhas de fuga. Em Filosofia, diferente do que se defende comumente, não se interpreta, mas se cria, sem caminho certo ou errado, sem a centralização em conceitos norteadores; são linhas que escapam e se esbarram, que contrariam, assim como os movimentos de Maio de 68, qualquer tentativa de fechá-las, moldá-las. São potências contra as estruturas. "Toda vez que uma multiplicidade se encontra presa numa estrutura, seu crescimento é compensado por uma redução das leis de combinação". (DELEUZE; GATTARI, 1995, p. 14). Não se busca mais a compensação, mas a experiência: é isso que propôs Maio de 68.

Com base nessas motivações teórico-práticas, Deleuze se engajou em uma organização criada por Michel Foucault, no início dos anos 1970: o Grupo de Informações sobre as Prisões - GIP. Este grupo se organizou como um rizoma, de maneira completamente descentralizada, mantendo grupos de ativistas espalhados pela França, especificamente, onde alguns ativistas encontravam-se presos.

\footnotetext{
${ }^{1}$ Etimologicamente, esquizofrenia diz respeito à ruptura de elementos fundamentais do corpo e da mente - schiz: divisão, cisão, fenda (Miller-Keane Encyclopedia and Dictionary of Medicine, Nursing, and Allied Health, 2003); phreni: mente, coração ou diafragma (Farlex Partner Medical Dictionary, 2012).
} 
Deleuze vê nessa organização uma possibilidade de criar uma resistência prática e eficaz que, ao mesmo tempo, segundo Dosse (2010, p. 158), havia rompido com o centralismo, definindo-se como uma microestrutura. Em uma aula ministrada na Universidade de Paris 8, em 28 de janeiro de 1986, com irreverência, Deleuze afirmou que "O GIP desenvolveu um dos únicos grupos de esquerda, funcionando sem centralização... Foucault conseguiu não se comportar como um líder". (apud DOSSE, 2010, p. 15).

Encabeçado por intelectuais engajados do seu tempo, como Foucault, Sartre, Claude Mauriac, Hélène Cixous, Pierre Faye, Jacques Donzelot, dentre muitos outros, o GIP encarnava o espírito de ação para Deleuze, promovendo intervenções reais contra a desumanização dos presos políticos, esmagados pela máquina repressora e autoritária do Estado. Segundo ele, a expressão dos prisioneiros era algo inteiramente novo, que deixava de ser uma "confissão pública", sendo mais uma "crítica personalizada": "Chegará o dia em que nenhum guarda poderá agredir um detento sem que, no dia seguinte, ou um mês depois, ele seja publicamente denunciado por aquele que foi espancado ou por alguma testemunha", diz Deleuze em um artigo intitulado "O que os presos esperam de nós...", publicado no Le Nouvel Observateur. (apud DOSSE, 2010, p. 160).

Além das ações referentes às prisões, o GIP se mobilizou também em torno da repressão e do racismo, fazendo com que esses atos de militância e resistência proporcionassem um diálogo sobre a definição das novas missões dos intelectuais na sociedade. Deleuze via no GIP uma possibilidade de renovar a relação entre teoria e prática, colocando a Filosofia em um contexto mais concreto, real, local e parcial. "Para nós, o intelectual teórico deixou de ser um sujeito, uma consciência representante e representativa”, diz Gilles Deleuze em um artigo intitulado "Les intellectuels et le pouvoir", publicado em 4 março de 1972 (apud DOSSE, 2010, p. 161); o intelectual desse tempo não é mais visto como a encarnação da verdade, mas favorece a democratização dos conhecimentos para que as pessoas possam ter condições de falar por si mesmas.

Enquanto o GIP era para Deleuze o ponto de encontro providencial entre a filosofia engajada e os problemas políticos e sociais do seu tempo, Guattari estava envolvido com uma série de práticas sociais ligadas à militância, muitas ligadas a instituições de pesquisa, como o CERFI - Centro de Estudos, de Pesquisa e de Formação Institucionais, que eram lugares de experimentação de conceitos, elaborados em conjunto com Deleuze

Em Capitalismo e Esquizofrenia (vol. 1 e vol. 2), esses intelectuais criticaram abertamente a abordagem e o alcance do método psicanalítico para análise das engrenagens da máquina social dominada pela produção e pelo capital. O imperialismo analítico do Complexo de Édipo é questionado em favor da percepção da complexidade do sujeito, o qual é subjugado pela máquina capitalista que não cessa de produzir ações, afetos, comportamentos, registros, consumos, angústias, avarias: produção de produção, processo que tem no desejo o seu princípio imanente. 
De base marxista, mas também apontando as limitações dessa corrente, as discussões de Deleuze e Guattari voltam sua atenção justamente para o sujeito envolvido nesse processo, o qual é também visto como uma máquina programada para produzir. O indivíduo é atrelado a uma engrenagem de produção e consumo definida pelo princípio do desejo, que é também gerado e gerido pelo sistema, fazendo assim a roda capitalista girar infindamente, direcionada pela mais-valia. "O próprio sujeito não está no centro, ocupado pela máquina, mas na borda, sem identidade fixa, sempre descentrado, concluído dos estados pelos quais passa”. (DELEUZE; GUATTARI, 2010, p. 35).

Todavia, não é o capitalismo que inventa a produção, ele só a manipula e a tenciona, uma vez que, segundo os filósofos, o desejo é o princípio de conexão de todas as coisas (máquinas desejantes), resultando na produção de fluxos, como a máquina-boca do filho que se conecta à máquina-mama da mãe para que esta produza leite. Esse agenciamento e troca de fluxos só acontece pelo desejo (fome ou ato sexual edipiano, como diria Freud). É justamente por entender a dinâmica da produção desejante que a produção social capitalista se estabelece, perscrutando e explorando os desejos e necessidades humanas (desejos mais urgentes que se estabelecem como prioridades indispensáveis) a fim de direcionar os fluxos e determinar comportamentos.

Em contrapartida, nesse paralelo que se estabelece entre a produção social e a produção desejante, surge sorrateiramente, como consequência inevitável, "uma instância de antiprodução pronta a assentar-se sobre as formas produtivas e apropriar-se delas". (DELEUZE, GUATTARI, 2010, p. 49). É nesse sentido que os filósofos franceses afirmam que o capitalismo promove uma cisão em si mesmo, ou seja, esquizofreniza-se, porque desconsidera que as máquinas desejantes só produzem fluxo (produção desejante) quando são desarranjadas, ou seja, desterritorializadas de suas funções primeiras para estabelecer uma conexão com outra máquina, criando um devir, o desmonte das máquinas que são acopladas para o agenciamento de uma terceira coisa.

Ao contrário disso, as máquinas técnicas da indústria só funcionam organizadas, uma vez que são compostas de engrenagens e estruturas justapostas, e seu limite se encontra no desgaste causado pelo uso e pelo tempo. É justamente por essa discrepância que a lógica de funcionamento do capitalismo tende a avariar todo o sistema e suas próprias peças, ou seja, as máquinas desejantes que estão acopladas à máquina capitalista, o que inclui os sujeitos. Essa instabilidade natural da vida expressa na dinâmica constante de devires, desterritorialização, reterrirorialização, conexões, desarranjos, etc., ameaça as estruturas conservadoras do sistema socioprodutivo (família, propriedade, estado), aquilo que Deleuze e Guattari (2010, p. 22) chamam de socius.

É nesse contexto que a Psicanálise é legitimada pelo socius como um método de tratamento para os indivíduos que são avariados a ponto de comprometerem o sistema de produção. A principal crítica dos filósofos franceses à abordagem de Freud é que esta não se constitui em 
nenhum momento como uma possibilidade de revolução, uma chance de quebrar as amarras maquínicas que deixam os homens "doentes", incapazes de cumprir os protocolos das funções sociais; a psicanálise apenas se apresenta como uma alternativa viável para a reabilitação dos sujeitos: uma espécie de oficina, onde máquinas e suas peças são consertadas para que voltem a funcionar conforme a demanda da produção.

De fato, as descobertas teóricas de Freud foram singulares na sua época, teorizando as estruturas psíquicas, como a tríade consciente, inconsciente e subconsciente, e sugerindo formas de tratar os possíveis transtornos pelos quais a psique humana poderia passar. É a proposta da Psicanálise que percebe a produção latente dos desejos humanos (máquinas desejantes), mas a redução de toda complexidade psíquica a apenas um método de abordagem (Complexo de Édipo) oculta toda essa descoberta e reduz o plano de alcance analítico: "substituiu-se o inconsciente como fábrica por um teatro antigo; substituíram-se as unidades de produção inconsciente pela representação; substituiu-se o inconsciente produtivo por um inconsciente que podia tão somente exprimir-se (o mito, a tragédia, o sonho...)". (DELEUZE; GUATARRI, 2010, p. 40).

As atitudes desregradas do homem transtornado, rebelde, insubmisso, como os esquizofrênicos, que se negam ao tratamento pela edipianização, então, passam a ser tratadas como representações do inconsciente sobre um palco de teatro, quando a psique deveria ser considerada, de acordo com os filósofos, como uma usina, uma fábrica de intensa produção desejante, experimentação, conexões e devires. O imperialismo analítico do Complexo de Édipo reprime as manifestações voluntárias das máquinas desejantes e passa a considerar o desejo como falta de alguma coisa real, e essa ausência produz o que Freud chamou de fantasmas.

De fato, Deleuze e Guattari são muito enfáticos em sua aversão à proposta de Freud, que particularmente depositava o sujeito esquizo às margens da atenção psicanalítica, e assim sugerem uma proposta de análise alternativa, contrária e bastante irônica: a Esquizoanálise. No entanto, não é possível delimitar as características desse novo "método", uma vez que isso seria estabelecer parâmetros nos quais os sujeitos seriam mais uma vez rotulados, justamente o que fazia a psicanálise. Dessa forma, convém observar o sujeito em processo, em seus devires e experiências, a fim de analisá-lo de forma específica, considerando as múltiplas variantes que fazem parte de sua constituição enquanto indivíduo.

Refletindo sobre as condições capitalistas do socius que esquizofrenizam os sujeitos, a ponto de se tornarem uma ameaça à ordem benquista das coisas, Deleuze e Guattari (2015, p. 119-120) afirmam, contrariando a tentação reducionista das ciências sociais, que Maio de 1968

[...] foi um fenômeno de vidência, como se uma sociedade visse, de repente, o que ela tinha de intolerável, e visse também a possibilidade de outra coisa. É um fenômeno coletivo na forma de: "Um pouco de possível, senão eu sufoco...” O possível não preexiste, é criado pelo acontecimento. É uma questão de vida. O acontecimento cria uma nova existência, produz uma nova subjetividade (novas relações com o corpo, 
o tempo, a sexualidade, o meio, a cultura, o trabalho...). Quando uma mutação social surge, não basta extrair dela todas as consequências ou efeitos, segundo linhas de causalidade econômicas e políticas. É preciso que a sociedade seja capaz de formar agenciamentos coletivos que correspondam à nova subjetividade, de tal maneira que ela queira a mutação. Isso é uma verdadeira "reconversão".

Todavia, não foi isso que aconteceu na França, infelizmente. Deleuze e Guattari lamentam em um texto intitulado "Maio de 68 não ocorreu", de 1984, uma vez que, para eles, os acontecimentos de Maio de 68 não foram a consequência ou reação de uma crise, mas foi a crise vivida pela sociedade francesa da época que impossibilitou que tal movimento revolucionário pudesse ser compreendido.

Maio de 68 foi a ponta de um iceberg e sua potência não acabou após o término das manifestações, das greves, quando la beautéz saiu das ruas para se institucionalizar novamente e ganhar força nas universidades - quisera Deleuze e Guattari que isso fosse pela descentralização do poder, mas infelizmente não é bem esse cenário que constatamos.

Os filhos de maio de 68 podem ser encontrados espalhados por aí, ainda que eles próprios não saibam, e cada país os produza à sua maneira. A situação deles não é muito animadora. Não são jovens bem-sucedidos. São estranhamente indiferentes e, no entanto, muito informados. Deixaram de ser exigentes, ou narcisistas, mas sabem muito bem que nada responde atualmente à sua subjetividade, à sua capacidade de energia. Sabem inclusive que todas as reformas atuais vão até contra eles. Estão decididos a cuidarem da própria vida, o melhor que puderem. Preservam uma abertura, um possível. (DELEUZE; GUATTARI, 2015, p. 2).

Assim como, na primavera de 1971, Alain Jaubert presenciou a truculência da polícia durante uma manifestação de antilhanos e acabou sendo levado num camburão e espancado pelos policiais militares (apud DOSSE, 2010, p. 161), os filhos de Maio de 1968 ainda continuam sendo massacrados pela polícia, pelo poder dos Governadores, que batem e atiram até mesmo em professores da rede pública de ensino, que se organizam e ocupam espaços públicos, do povo, como a Assembleia Legislativa ou o Ministério da Justiça, como aconteceu em Paris, em 17 de janeiro de 1972. Todavia, como citaram Deleuze e Guattari, é necessário que a sociedade crie novos agenciamentos sociais para comportar a revolução que cresce um pouco mais a cada dia pela voz dos filhos de Maio de 1968; é preciso corresponder a essa nova e desafiante subjetividade e querer a mutação. Só assim é que a real "reconversão" pode acontecer.

\footnotetext{
${ }^{2}$ La beautéest dans la rue (A beleza está na rua) é uma frase de um famoso cartaz feito para as manifestações de Maio de 1968. O cartaz retrata uma pessoa (provavelmente, uma mulher) atirando um paralelepípedo (contra a polícia?) em uma posição que faz clara alusão a Marianne, símbolo da República Francesa, no quadro La Liberté guidant le peuple -A liberdade guiando o povo (1830), de Eugène Delacroix (1798-1863).
} 


\section{REFERÊNCIAS}

DOSSE, F. Os engajamentos políticos de Gilles Deleuze. História: Questões \& Debates, Curitiba, n. 53, p. 151-170, jul./dez. 2010. Disponível em: <https://revistas.ufpr.br/historia/ article/viewFile/24120/16151>. Acesso em: 03 abr. 2018.

DELEUZE, G.; GUATTARI, F. Maio de 68 não ocorreu. Revista Trágica: estudos de filosofia da imanência, Rio de Janeiro, v. 8, n. 1, p. 119-121, jan./abr. 2015. Disponível em: <http://tragica. org/artigos/v8ni/traducao.pdf>. Acesso em: 05 abr. 2018.

DELEUZE, G.; GUATTARI, F. Mil platôs: capitalismo e esquizofrenia 2, vol. 1. Tradução de Aurélio Guerra Neto e Celia Pinto Costa. São Paulo: Ed. 34, 1995.

DELEUZE, G.; GUATTARI, F. O Anti-Édipo: capitalismo e esquizofrenia 1. Tradução de Luiz B. L. Orlandi. São Paulo: Ed. 34, 2010.

LA BEAUTÉ est dans la rue [Cartaz]. Montpellier, 1968. Disponível em: <https://gallica.bnf.fr/ ark:/12148/btvib9018366v>. Acesso em 02 abr. 2018.

PALOMBINI, A de L. Lacan, Deleuze e Guattari: escritas que se falam. Psicologia \& Sociedade, Florianópolis, v. 21, n. esp., p. 39-42, 2009. Disponível em: <http://www.scielo.br/pdf/psoc/ v21nspe/v21nspea07.pdf>. Acesso em: 15 abr. 2018.

PHRENI. In: Farlex Partner Medical Dictionary. 2012. Disponível em: $<$ http://medicaldictionary.thefreedictionary.com/phreni->. Acesso em: 08 ago. 2016.

PINTO, J. A. da C. França: lutas sociais anticapitalistas no maio de 1968. Revista Espaço Acadêmico, Maringá, v. 9, n. 85, p. 1-5, jun. 2008. Disponível em: <http://www.espacoacademico. com.br/085/85pinto.pdf>. Acesso em: 11 mar. 2016.

SCHIZ-. In: Miller-Keane Encyclopedia and Dictionary of Medicine, Nursing, and Allied Health. 7. Ed, 2003. Disponível em: <https://medical-dictionary.thefreedictionary.com/schiz->. Acesso em: 08 ago. 2016.

Recebido para publicação em 25 set 2018. Aceito para publicação em 14 mar. 2019. 